\title{
Use of Logistic Regression Model for Prediction of Non-Timber Forest Products
}

\author{
Alexandre Leandro Santos de Abreu*, Ricardo de Oliveira Gaspar, \\ Mirella Basileu de Oliveira Lima, Mauro Eloi Nappo, Eraldo Aparecido Trondoli \\ Department of Forest Science, University of Brasilia, Brasília, Brazil \\ Email: *alexandre.abreuenf@yahoo.com.br
}

How to cite this paper: de Abreu, A.L.S., de Oliveira Gaspar, R., de Oliveira Lima, M.B., Nappo, M.E. and Trondoli, E.A. (2017) Use of Logistic Regression Model for Prediction of Non-Timber Forest Products. American Journal of Plant Sciences, 8, 2847-2859. https://doi.org/10.4236/ajps.2017.811193

Received: September 22, 2017

Accepted: October 27, 2017

Published: October 30, 2017

Copyright $\odot 2017$ by authors and Scientific Research Publishing Inc. This work is licensed under the Creative Commons Attribution International License (CC BY 4.0).

http://creativecommons.org/licenses/by/4.0/

\begin{abstract}
The use of non-timber is a valuable alternative for the conservation of tropical forests. Juçara (Euterpe edulis Mart.) is considered one of the main alternatives in the Atlantic Forest for the production of açaí pulp. However, there are few studies that aim to evaluate their production. The present study aimed to construct a probabilistic model to predict the production of Euterpe edulis bunches, using dendrometric variables and competition index. Twenty plots of $10 \times 50 \mathrm{~m}$ were sampled in an area with said specie, showing the arboreal entities with diameter at breast height $>4.8 \mathrm{~cm}$, and recording the Euterpe edulis phenomena. The main variables influencing the production of bunches were assessed using logistic regression model. The logistic regression showed the variables diameter breast height $(\mathrm{DBH})$ and total height $(\mathrm{h})$ as significant to explain the variation between productive and non-productive entities. The competition index tested was not significant ( $\mathrm{p}$-value $=0.221$ ). The model of prediction of curl production in Juçara can be written as: $Z_{i}=-6.878594+$ $0.2522454 \times \mathrm{DBH}+0.1951574 \times \mathrm{h}$. The use of a logistic regression model showed potential for prediction of non-timber forest products.
\end{abstract}

\section{Keywords}

Forest Management, Regression Model, Logit, Euterpe edulis Mart

\section{Introduction}

The suppression of forests throughout history in order to develop land for other uses has reduced the Atlantic Forest to fragments, threatening the biodiversity of the Brazilian biome [1]. Currently, there is only $12 \%$ of the original Atlantic Forest coverage, with less than half of on protected areas [2]. Most of the agricultural land of Brazil, as well as most of the country's population, 125 million 
inhabitants, are located in this biome.

Governments and nongovernmental organizations (NGOs) have supported rural communities as a way to promote conservation and sustainability of tropical forests in Latin America and the world [3]. Their actions are often directed towards the use of non-timber forest products (NTFP). For instance, in Brazil the National Plan for the Promotion of Socio-biodiversity Products was implemented in 2009 [4].

There is, however, scarce information on the production and sources of NTFP variation of commercial interest. Since NTFPs are considered an important component in tropical forest conservation strategies, this supposes a contradiction [5].

The Juçara palm (Euterpe edulis Mart.) is one of the most important, abundant and valuable non-timber forest products exploited in the Atlantic Forest. The extraction of palm heart is its main use [1]. The collection of palm heart involves logging entities. This causes the death of the plant, since it has a single stipe and does not regrow [6]. Secretly exploited in sections of the Atlantic Rainforest, palm heart harvest has been the greatest threat to the species [7].

The exploitation of fruits for pulp production is a recent option of economic use that generates low impact on the Euterpe edulis population [8]. The product is equivalent to the Amazonian açaí, produced by Euterpe oleracea Mart. It is widely consumed today, due to its nutritional and health perspectives, such as the high energy, mineral and anthocyanin levels [7].

Juçara is one of the few tropical species with potential for commercial exploitation. It can be cultivated in native forests through sustainable management practices that guarantee the conservation of the remaining forest fragments [9]. The increasing interest in the management of the species for pulp production makes it necessary to further study the variation in fruit productivity and its causes [10].

Some recent studies have evaluated Euterpe edulis fruit production, however, no methodologies are proposed for using field survey data to estimate yield [10] [11]. Neither are there variables that quantify the competition suffered by sampled entities in models constructed for Juçara fruit production assessment.

Studies on competition among tree entities have received great attention because of their strong effects on control in the structure and development of stands [12]. Competition between trees takes place when there is a scarcity of resources: production decreases below entity demand [13].

In growth models and forest production, tree competition is an important quantitative variable [14]. However, as authors report, this is difficult to measure because their direct causes are not known. There are three categories for competition indices [14]: distance independent, which use variables at settlement level; distance dependent, which insert size and location of neighboring or competing trees with the object tree; and distance semi-independent, which are calculated by considering the neighboring trees in circular plots around the object tree. 
This investigation aimed at constructing a probabilistic model to predict the production of Euterpe edulis bunches; using dendrometric variables and competition index.

\section{Materials and Methods}

\subsection{Study Area and Collection of Data}

The present study was carried out in fragments of the Semideciduous Seasonal Forest belonging to the Dênis Gonçalves Settlement Project (21 $34^{\prime} 30^{\prime \prime S}$ and $\left.43^{\circ} 12^{\prime} 33^{\prime \prime W}\right)$, located in Zona da Mata/Minas Gerais, in February and March 2016 (Figure 1). The study area is between $409 \mathrm{~m}$ and $928 \mathrm{~m}$ of altitude. Latosols is the predominant soil class [15]. The climate in the region is classified as Cwb (Köppen), its altitude as tropical, mesothermic, with hot summers and high precipitation (October to April), and cold and dry winters (May to September) [16]. The annual average temperature is $18.7^{\circ} \mathrm{C}$ and annual rainfall of $1528 \mathrm{~mm}$.

Fragments in the settlement are of secondary forest and total 1393.8 ha. They are kept in the Legal Reserve-areas in the interior of rural properties that are destined for conservation, described in the Brazilian Law [17]. These are previously planted with Coffea arabica L, and that have been destined to natural regeneration for more than 60 years (personal communication).

Areas were first identified in order to quantify and measure Euterpe edulis entities. Parcels of forest inventory were randomly allocated at these sites.
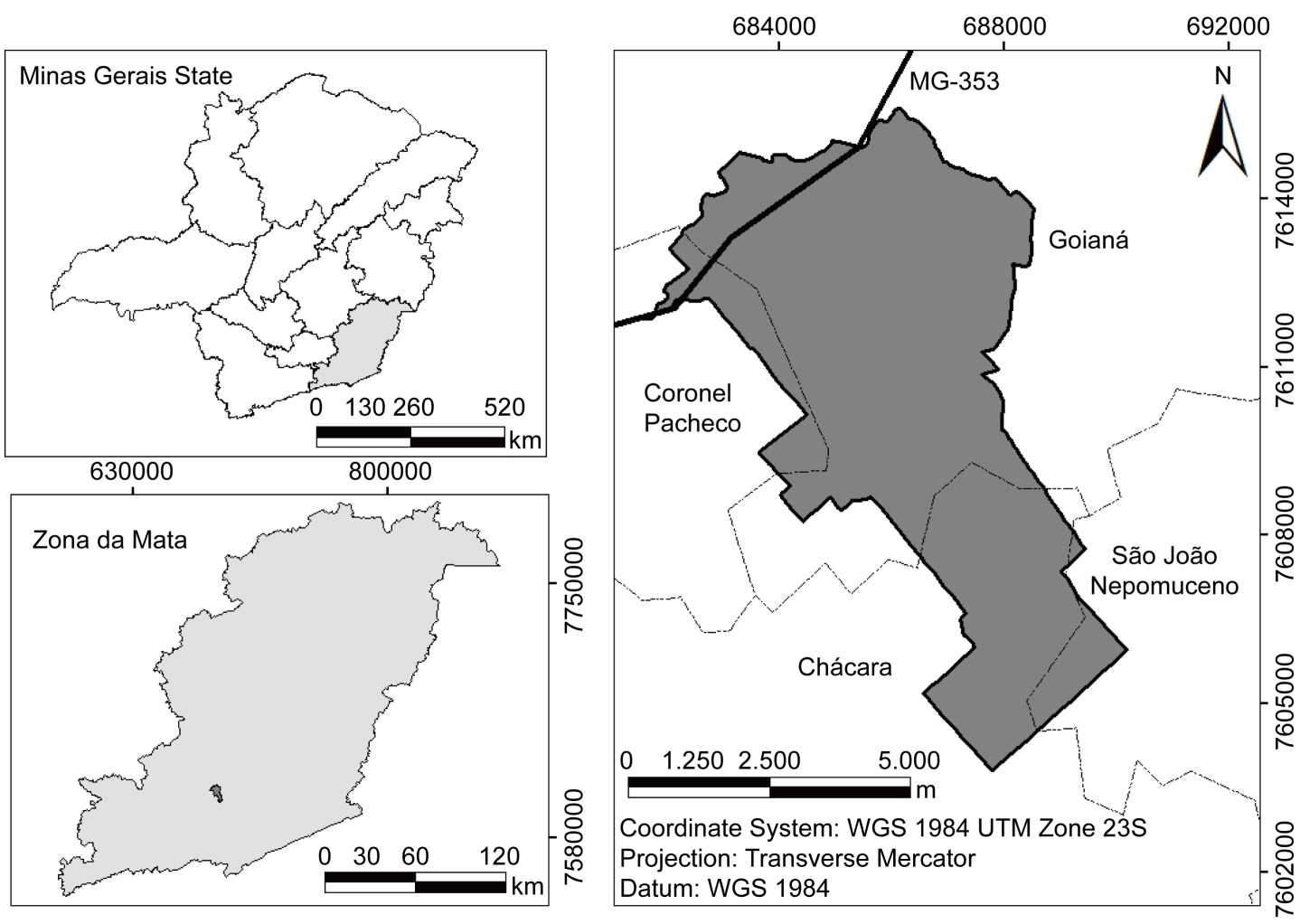

Figure 1. Study area location (Dênis Gonçalves Settlement Project, meso-region Zona da Mata/Minas Gerais). 
Twenty plots of $500 \mathrm{~m}^{2}(10 \times 50 \mathrm{~m})$ were measured, totaling a sampling effort of one hectare.

All living and dead standing shrubs, with circumference at breast height $(\mathrm{CBH})$ equal to or greater than $15.0 \mathrm{~cm}(\mathrm{DBH} \geq 4.8 \mathrm{~cm})$, were sampled. Each entity's scientific name, $\mathrm{CBH}$ value measured with tape measure, total height, and pheno-phase were recorded. Identification of the botanical material was carried out by consulting the literature, specialists or by comparisons with specimens present in the herbarium of University of Brasília, according to the classification system APG III [18].

\subsection{Data Analysis}

Distance-independent competition indices (IID) [19] were calculated calculated in order to assess each Euterpe edulis entity's competition (Table 1).

$\mathrm{DBH}$, total height $(\mathrm{h})$ and $I I D_{1}$ were selected using Pearson correlation coefficients (Table 2) for the construction of the bunches production model for occurrence probability. As for the significance test alpha $=0.05$, the $p$-value was lower than $2.2 \mathrm{e}-16$ for all indices.

Sampled individuals were stratified by their diametrical distribution and vertical structure, in order understand the influence of dendrometric variables on the production of Juçara clusters. The definition of vertical strata followed the criteria described by [20] (Table 3). Strata were calculated by plot, including all sampled tree entities, of all species found.

Table 1. Competition-independent distance indices calculated in the study.

\begin{tabular}{cll}
\hline Competition indices & Author (year) & Equation \\
\hline$I I D_{1}=\frac{A S_{i}^{2}}{A S q^{2}}$ & STAGE (1973) \\
$I I D_{2}=B A L_{i}$ & STAGE (1973)
\end{tabular}

Where: $A S_{i}=$ shaft sectional area of object tree, measured at 1.30 height $\left(\mathrm{m}^{2}\right), A S q=$ sectional area corresponding to the average diameter $(\mathrm{q})$ of neighboring tree shafts $\left(\mathrm{m}^{2}\right) ; B A L_{i}=$ sum of the sectional areas of neighboring tree shafts larger than the object tree's stem.

Table 2. Correlation between dendrometric variables, number of bunches and indexes of competition.

\begin{tabular}{cccccc}
\hline & Bunches & $h$ & $D B H$ & $I I D_{1}$ & $I I D_{2}$ \\
\hline Bunches & 1 & & & & \\
$\mathrm{H}$ & 0.5719 & 1 & & & \\
$\mathrm{DBH}$ & 0.5304 & 0.8269 & 1 & 1 & \\
$I I D_{1}$ & 0.4334 & 0.5639 & 0.7917 & 0.7308 & 1 \\
$I I D_{2}$ & -0.4221 & -0.5667 & -0.7208 & & \\
\hline
\end{tabular}

Where, $h=$ Juçara entity height; $\mathrm{DBH}=$ diameter at 1.30 of soil; $I I D_{1}=$ competition index $01 ; I I D_{2}=$ competition index 02 . 
Table 3. Height stratification of sampled forest stands.

\begin{tabular}{cc}
\hline Stratum & Formula \\
\hline Lower & $h<h m-1 S$ \\
Meddle & $h m-1 \mathrm{~S} \leq \mathrm{h}<h m+1 \mathrm{~S}$ \\
Upper & $h \geq h m+1 \mathrm{~S}$ \\
\hline
\end{tabular}

Where, $h=$ total height for each entity; $h m=$ average height for sampled entities; $S=$ standard deviation for average height.

The Logit probability model was chosen for the estimation of bunches production probability in Euterpe edulis entities. This model has been used in several studies and in different areas, such as biology, epidemiology, medicine, economics, engineering, and others [21].

Model of a limited dependent variable, the regressing is a binary variable. It may assume two values; 1 if there is an occurrence of the event and 0 otherwise [22]. Thus, these results show the probability of production for a given Juçara entity, given their values of diameter, total height and competition index. All sampled entities from the species were used. There was a variable number of bunches ranging from 0 to 4 bunches. These were transformed into a binary.

The logistic distribution is used as a link function in the Logit model:

$$
P_{i}=E\left(Y=1 \mid X_{i}\right)=f(\beta X)
$$

where, $P_{i}$ is the chances of $i$ entity of producing at least one cluster of fruits; $f$ is the cumulative distribution function; $X$ is a vector of explanatory variables; and $\beta$ are unknown parameters to be estimated. The representation of this relation in the Logit model follows the following form:

$$
P_{i}=E\left(Y=1 \mid X_{i}\right)=\frac{1}{1+e^{-(\beta X)}}=\frac{e^{(Z)}}{1+e^{(Z)}}
$$

where $Z_{i}=\beta X$, where $\beta$ are unknown parameters, and $X$ is the vector of explanatory variables.

If occurrence probability of production of the Juçara entity is $P_{i}$, and the non-occurrence is $\left(1-P_{i}\right)$. Thus, dividing the probability of occurrence by non-occurrence:

$$
\frac{P_{i}}{1-P_{i}}=\frac{1+e^{Z i}}{1+e^{-Z i}}=e^{Z i}
$$

Equation (5) represents the ratio of the chances of a palm tree to produce; the division between the probabilities that Juçara entity produces, by the probability that there is no production. Taking the natural logarithm of equation (5) the logit (L):

$$
L_{i}=\ln \left(\frac{P_{i}}{1-P_{i}}\right)=Z_{i}=\beta X
$$

Therefore, the logarithm of odds ratio (logit), $L_{i}$, is a linear function of the explanatory variables and the calculated parameters. 
The parameters of the Logit model are estimated by the maximum likelihood (MV) method. This method's goal is to maximize the likelihood function, that is, to obtain values for the still unknown parameters that maximize the possibility of observing the data of the dependent variable presented in the input matrix.

The logistic function is expressed in this way in this study:

$$
\ln \left(\frac{P_{i}}{1-P_{i}}\right)=\beta_{1}+\beta_{2} D B H+\beta_{3} h+\beta_{4} I I D_{1}
$$

where, DBH is the diameter at chest height, $h$ is the total height of the Euterpe edulis entity, IID $D_{1}$ the 1 calculated competition index, and $\varepsilon$ the random error.

The estimated coefficients provide the variation in Logit from the change of one unit of the independent variable. Parameters positive values mean that an increase in the independent variable will return an increase in the probability of occurrence of the phenomenon, ergo, they are directly proportional. Negative values for the regressors mean an inversely proportional relation, in which the increase of the independent variable means the decrease of the probability of occurrence of the phenomenon.

The hypothesis is that the parameters resulting from the application of the Logit model are positive, with a prediction that the increase in diameter, height and competition index values (with decreased competition) positively affect the probability of Juçara bunches.

Chi-square test function, LR, was applied in order to test the null hypothesis, where estimated coefficients are expected to simultaneously equal zero. Similar to the $\mathrm{F}$ test for simple linear regression models, the likelihood ratio follows the statistical distribution $\chi^{2}$, where the number of degrees of freedom is equal to the number of independent variables in the model [22].

The quality of fit in binary regression models does not follow the conventional measure of adjustment quality, $R^{2}$. Similar measures are employed, called pseudo $R^{2}$ [22]. McFradden's $R^{2}$ ( $R_{M c F}^{2}$ ) and count $R^{2}$ were used in this study.

The model was re-assessed without the non-significant variables, to test whether the withdrawal would affect the adjustment. The calculations of the present work were carried out using Stata/SE 12.0 software [23].

\section{Results and Discussion}

\subsection{Entity Distribution according to Diametric Class and Height Stratification}

809 Euterpeedulis entities were sampled in the floristic survey, where 208 were in reproductive phenomena, with a total 373 clusters.

The distribution of the Juçaras in diameter classes showed a higher production concentration in the diameter classes between $15 \mathrm{~cm}$ and $20 \mathrm{~cm}$, with $59.62 \%$ of productive individuals and $63 \%$ of observed cluster production. Table 4 also shows that, with increasing diameter, the proportion of productive individuals in relation to the total class also increases, with production in all individuals in the class between $25 \mathrm{~cm}$ and $30 \mathrm{~cm} \mathrm{DBH}$. 
Table 4. Diameter distribution of Juçara entities and cluster amount per diameter class.

\begin{tabular}{|c|c|c|c|c|c|c|}
\hline & \multicolumn{5}{|c|}{ Class center $(\mathrm{cm})$} & \multirow[b]{2}{*}{ Tota } \\
\hline & 7.5 & 12.5 & 17.5 & 22.5 & 27.5 & \\
\hline Number of individuals Euterpe edulis & 284 & 280 & 218 & 24 & 3 & 809 \\
\hline$\%$ of individuals E.edulis in relation to the total sampled & 35.11 & 34.61 & 26.95 & 2.97 & 0.37 & \\
\hline Individuals with bunch & 0 & 65 & 124 & 16 & 3 & 208 \\
\hline$\%$ of Euterpe edulis with bunch & 0.00 & 31.25 & 59.62 & 7.69 & 1.44 & \\
\hline$\%$ of Euterpe edulis with bunches in relation to diameter class & 0.00 & 23.21 & 56.88 & 66.67 & 100.00 & \\
\hline Number of bunches & 0 & 104 & 235 & 29 & 5 & 373 \\
\hline$\%$ of production & 0.00 & 27.88 & 63.00 & 7.77 & 1.34 & \\
\hline
\end{tabular}

Minimum observed height of sampled Juçara entities was 2 meters; maximum height was 27 meters, achieving a mean value of $10.13 \pm 5.45$. The vertical stratification of the forest demonstrates a directly proportional relationship, as presented for DBH, between height increase and bunches production (Table 5).

Juçara entities represent $25.34 \%$ in the upper stratum. This stratum concentrates $66.22 \%$ of registered bunches, and has a higher proportion of productive individuals than non-productive individuals, compared to the middle stratum. $65.85 \%$ of the individuals in the upper stratum produced, while only $15.70 \%$ of the individuals in the middle stratum presented reproductive phenomena.

The highest entity concentration was naturally expected in the meddle height stratum, due to the expression that determined the vertical stratification. Yet, Euterpeedulis entities in the upper stratum had an expressive percentage of individuals in reproductive phase indicating that there is a strong relationship between curl production and the vertical position. This provides a valuable contribution to the handling of specie curls and fruits.

Juçara characteristics in cluster production in the Semideciduous Seasonal Forest had similar results in this study to those found in other research with the species in the Dense Ombrophylous Forest [6] [10] [11] [24]. Studies in seasonal forest should be continued in order to deepen the understanding of the characteristics of the species in this phytophysiognomy, subsidizing its management.

\subsection{Model Adjustment}

The Logistic Model of Multiple Regression established DBH and Total Height as statistically significant (Table 6). The competition index did not statistically influence bunch production.

The chi-square LR value was 355.15 . This implied the rejection of the Ho hypothesis. Therefore, coefficients are jointly significant to explain the production of bunches in Euterpe edulis.

The count $R^{2}$ value, which established the amount of correct predictions in relation to the total number of observations, was 0.8232 . This indicates that the model predicts $82.32 \%$ of observations correctly. The $R_{M C F}^{2}$ value was 0.3851 , 
Table 5. Euterpe edulis distribution and bunches production, where: Lower $=h<h m-1 S$; Meddle $=h m-1 \mathrm{~S} \leq h<h m+1 \mathrm{~S}$; and Upper $=h \geq h m+1 S$.

\begin{tabular}{|c|c|c|c|c|}
\hline & \multicolumn{3}{|c|}{ Stratum } & \multirow[b]{2}{*}{ Total } \\
\hline & Lower $(h<5 \mathrm{~m})$ & Meddle $(5 \mathrm{~m}<h<12 \mathrm{~m})$ & Upper $(h>12 \mathrm{~m})$ & \\
\hline Number of individuals Euterpe edulis & 139 & 465 & 205 & 809 \\
\hline$\%$ of individuals Euterpe edulis in relation to the total sampled & 17.18 & 57.48 & 25.34 & - \\
\hline Individuals with bunch & 0 & 73 & 135 & 208 \\
\hline$\%$ of Euterpe edulis with bunch & 0.00 & 35.10 & 64.90 & - \\
\hline$\%$ of Euterpe edulis with bunches in relation to height classes & 0.00 & 15.70 & 65.85 & - \\
\hline Number of bunches & 0 & 126 & 247 & 373 \\
\hline$\%$ of production & 0.00 & 33.78 & 66.22 & - \\
\hline
\end{tabular}

Table 6. Logit results for the estimation of Euterpe edulis production probability.

\begin{tabular}{|c|c|c|c|c|c|}
\hline Variable & Coefficient & Standard error & Z-test & $\mathrm{P}>|\mathrm{z}|$ & Marginal effect \\
\hline Intercept & -6.323475 & 0.6721335 & -9.41 & $0.000^{\star *}$ & - \\
\hline DBH & 0.1791376 & 0.0709782 & 2.52 & $0.012^{\star}$ & 0.0212956 \\
\hline $\mathrm{H}$ & 0.2108151 & 0.0322717 & 6.53 & $0.000^{\star \star}$ & 0.0250614 \\
\hline IID1 & 0.1543895 & 0.1260487 & 1.22 & $0.221 \mathrm{NS}$ & - \\
\hline
\end{tabular}

${ }^{*}$ significant coefficient at $5 \%,{ }^{* *}$ significant coefficient at $1 \%$, and NS non-significant parameter.

indicating that $38.51 \%$ of the variation of the dependent variable can be explained by the independent variables of the model. The pseudo $R^{2}$ value, below $40 \%$, does not necessarily indicate an insufficient adjustment, given the use of dendrometric variables to estimate a non-timber forest product. Moreover, in binary regression models, the quality of the adjustment is of secondary importance. The most important model relies on the significance and practice of the coefficients linked to explanatory variables [22].

Coefficients were positive. This shows that an increase on DBH and total height increase the probability of Juçara cluster production. The marginal effect indicates that while there is an average increase in the probability of phenomenon occurrence and other variables remain constant, there is a one-unit increase in the analyzed variable. The one-meter increase on height represents on average an increase of $2.5 \%$ points in the probability of producing bunches. With DBH, the increase in $1 \mathrm{~cm}$ represents, on average, a rise of $2.1 \%$ points in the production probability of a specific entity.

Another sensible interpretation in terms of the odds ratio is obtained by calculating the antilogarithm of the angular coefficients of each variable [22]. Thus, taking the antilogarithm of DBH and height coefficients, the values of 1.19 and 1.23 are respectively obtained. With each one-unit increase in DBH, the entity's chance to produce increases 1.19 times. Regarding height, the one-unit increase represents a 1.23 increase in production probability. 
Therefore, the importance of height in explaining Euterpe edulis cluster production is notorious. Height reflects the luminosity incident on the crown of the palm trees. Souza [10], when studying different forms of management of Juçara, observed an increase in fruit production and reduction of inter-annual variation through the practice of agroforestry management. The author highlights that the main altered morpho-climatic characteristic in this type of management is the luminosity pattern.

Shading is recognized as an important facilitation mechanism between pioneer and secondary species. However, it may also be a mechanism of inhibition, as species that demand more light for their development begin to suffer through their absence [25]. Forest composition and structure are products of the interaction between several factors, one of which is competition for light, in which each species traces different strategies [26].

Plant height is related to the position the entity occupies in the forest canopy, and with the availability of light incident on the crown of the palm tree [11]. The information available in Table 5 shows that entities in the upper stratum produce more bunches.

The luminosity was also registered as an important variable in natural regeneration studies. In an experiment conducted to evaluate the survival and growth of Euterpe edulis seedlings, Ribeiro et al. [9] obtained higher survival of the transplanted palm trees in clearing environments when compared to transplanted plants in the understory of the forest. A nonlinear regression generated a positive relation between canopy opening and seedling survival.

Withdrawing the competition index $I I D_{1}$, not significant in the model, did not change the significance in the re-estimation of the model (Table 7).

The chi-square LR value for the model with DBH and height was 353.56, rejecting the H0 hypothesis that coefficients equal zero. The count $R^{2}$ value, 0.8171 , indicated that $81.71 \%$ of predicted values are the same as observed. The $R_{M c F}^{2}$ value was 0.3834 , indicating that $38.34 \%$ of the variation of the dependent variable can be explained by DBH and $h$. These results demonstrate a low contribution of the competition index tested, given the reduced decrease in the fit quality of the model, when compared to the first adjustment. The DBH has a high correlation with $I I D_{1}(r=0.7917$, Table 2$)$, with multicollinearity between the variables.

Thus, the model of prediction of curl production in Juçara can be written as:

$$
Z_{i}=-6.878594+0.2522454 * D B H+0.1951574 * h
$$

Table 7. Logit results for the assessment of production probability of Euterpe edulis with independent variables DBH and $h$.

\begin{tabular}{cccccr}
\hline Variable & Coefficient & Standard error & Z-test & $\mathrm{P}>|\mathrm{z}|$ & Marginal effect \\
\hline Intercept & -6.878594 & 0.524556 & -13.11 & $0.000^{* *}$ & - \\
DBH & 0.2522454 & 0.0404434 & 6.24 & $0.000^{* *}$ & 0.0289351 \\
$\mathrm{~h}$ & 0.1951574 & 0.0292012 & 6.68 & $0.000^{* *}$ & 0.0223865 \\
\hline
\end{tabular}

${ }^{* *}$ significant coefficient at $1 \%$. 
where, $Z_{i}=\beta X, \mathrm{DBH}=$ diameter at breast height, $h=$ Euterpe edulis entity's total height.

Adding each entity's $\mathrm{Z}$ value to the algebraic formula representing logit bonding probability (Equation (4)), results in each entity's probability producing at least one cluster of fruits. The graphical representation of the production probability for all 809 sampled entities shows the sigmoid curve, characteristic of the cumulative distribution function (Figure 2).

It can be noted that in the re-estimated model, DBH had a greater contribution than height, given the higher value of its coefficient. Larger diameters are associated with individuals with greater use of available natural resources, such as water and nutrients. Recent studies have demonstrated a high relationship between the number of infructescences and palm diameter [10] [11].

Despite significant results from the model, there is a limitation to the present study worth noting: the single measurement of Juçara entities. Several studies have reported the variation in Euterpe edulis production between different years, occurring alternation of productive individuals and productivity per plant [10] [11] [27]. Another issue is fruit ripening. Paludo et al. [11] found $31.3 \%$ and $66.2 \%$ of the matrices in years of high and low production, respectively. Without the formation of mature fruits, the produce was aborted or pre-matured.

A long-term follow-up is necessary to evaluate specie behavior in Semidecidual Seasonal Forest, and, thus, to continue adjusting the model. Although the competition index tested in the present study was not significant, dependent and semi-independent indices of distance should be evaluated, since they may respond better to the probability of producing Juçara curls.

\section{Conclusions}

The use of a logit regression model demonstrated the potential for prediction of non-timber forest products. It allowed to specify the variables of greater contribution to production, which can be important in determining management practices.

Higher bunch production in the upper stratum $(h>12 \mathrm{~m})$ indicated the

Probability of production of individuals from Juçara

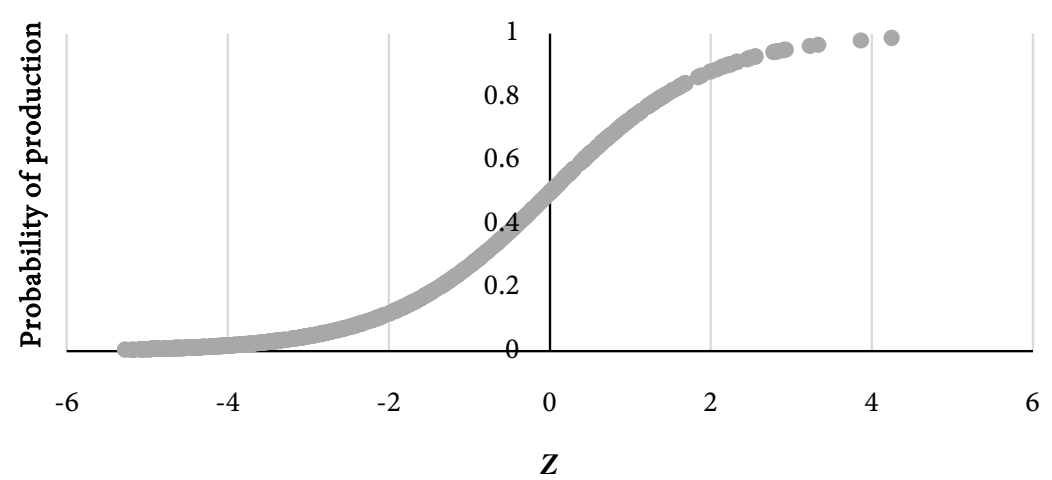

Figure 2. Curl production probability in the 809 sampled Juçara entities. 
strong relation between production and vertical stratification, subsidizing management alternatives.

The one-unit increase of measurement in DBH and $h$ increases by 1.19 times $(2.1 \%)$ and $1.23(2.5 \%)$ times, respectively, each entity's chance of production.

The competition, with use of the competition index not dependent on distance, was not significant.

\section{References}

[1] Fantini, A.C. and Guries, R.P. (2007) Forest Structure and Productivity of Palmiteiro (Euterpe edulis Martius) in the Brazilian Mata Atlântica. Forest Ecology and Management, 242, 185-194. https://doi.org/10.1016/j.foreco.2007.01.005

[2] Lapola, D.M., Martinelli, L.A., Peres, C.A., Ometto, J.P.H.B., Ferreira, M.E., Nobre, C.A., Aguiar, A.P.D., Bustamante, M.M.C., Cardoso, M.F., Costa, M.H., Joly, C.A., Leite, C.C., Moutinho, P., Sampaio, G., Strassburg, B.B.N. and Vieira, I.C.G. (2013) Pervasive Transition of the Brazilian Land-Use System. Nature Climate Change, 4, 27-35. https://doi.org/10.1038/nclimate2056

[3] Hajjar, R., McGrath, D.G., Kozak, R.A. and Innes, J.L. (2011) Framing Community Forestry Challenges with a Broader Lens: Case Studies from the Brazilian Amazon. Journal of Environmental Management, 92, 2159-2169. https://doi.org/10.1016/j.jenvman.2011.03.042

[4] Herrero-Jáuregui, C., Pokorny, B. and Casado, M. a. (2011) Coming Down to Earth: A Critical Analysis of a Project for the Commercialization of Non-Timber Forest Products in a Community of the Eastern Amazon. Pesquisa Florestal Brasileira, 31, 131-142. https://doi.org/10.4336/2011.pfb.31.66.131

[5] Kainer, K.A., Wadt, L.H.O. and Staudhammer, C.L. (2007) Explaining Variation in Brazil Nut Fruit Production. Forest Ecology and Management, 250, 244-255. https://doi.org/10.1016/j.foreco.2007.05.024

[6] Reis, M.S. Dos, Fantini, A.C., Nodari, R.O., Reis, A., Guerra, M.P. and Mantovani, A. (2000) Management and Conservation of Natural Populations in Atlantic Rain Forest: The Case Study of Palm Heart (Euterpeedulis Martius). Biotropica, 32, 894-902. https://doi.org/10.1111/j.1744-7429.2000.tb00627.x

[7] Muler, A.E., Rother, D.C., Brancalion, P.S., Naves, R.P., Rodrigues, R.R. and Pizo, M.A. (2014) Can Overharvesting of a Non-Timber-Forest-Product Change the Regeneration Dynamics of a Tropical Rainforest? The Case Study of Euterpeedulis. Forest Ecology and Management, Elsevier B.V., 324, 117-125.

[8] Milanesi, L., Peroni, N. and dos Reis, M. (2013) Use of the Palm Euterpeedulis Martius in Landscape Units Managed by Migrants of German Origin in Southern Brazil. Journal of Ethnobiology and Ethnomedicine, 9, 47. https://doi.org/10.1186/1746-4269-9-47

[9] Ribeiro, T.M., Martins, S.V., Lana, V.M. and Silva, K.A. (2011) Survival and Initial Growth of Euterpeedulis Mart. Seedlings Transplanted to Gaps and Undestory in a Semideciduous Forest, Viçosa, MG. Revista Árvore, 35, 1219-1226. https://doi.org/10.1590/S0100-67622011000700008

[10] Souza, S.E.X.F. (2015) Management of Euterpe edulis Mart. for Fruit Pulp Production: Subsidies to Biodiversity Conservation and Community Empowerment. Thesis, Escola Superior de Agricultura "Luiz de Queiroz", Piracicaba.

[11] Paludo, G., Da Silva, J. and Dos. Reis, M. (2012) Estimates of Palm Fruit Production 
(Euterpe edulis Mart.) from the Density of Individuals. Biodiversidade Brasileira, 2, 92-102.

http://www.icmbio.gov.br/revistaeletronica/index.php/BioBR/article/view/277

[12] Lustosa Junior, I.M. (2016) Competition and Modeling in a Fragment of Semi-Deciduous Seasonal Forest in Minas Gerais. Dissertation, Universidade de Brasília, Brasília.

[13] Weber, P., Bugmann, H., Fonti, P. and Rigling, A. (2008) Using a Retrospective Dynamic Competition Index to Reconstruct Forest Succession. Forest Ecology and Management, 254, 96-106. https://doi.org/10.1016/j.foreco.2007.07.031

[14] Martins, F.B., Soares, C.P.B., Leite, H.G., de Souza, A.L. and Castro, R.V.O. (2011) Competition Indexes for Individual Eucalyptus Trees. Pesquisa Agropecuária Brasileira, 46, 1089-1098. https://doi.org/10.1590/S0100-204X2011000900017

[15] Meier, M. (2016) Zoning Pedoenvironments in Agrarian Reform Settlement: Case Study-P.A. Denis Gonçalves, Zona da Mata, State of Minas Gerais. Dissertation, Universidade Federal de Viçosa, Viçosa

[16] Alvares, C.A., Stape, J.L., Sentelhas, P.C., Gonçalves, J.L.M. and Sparovek, G. (2014) Köppen's Climate Classification Map for Brazil. Meteorologische Zeitschrift, 22, 711-728. https://doi.org/10.1127/0941-2948/2013/0507

[17] Brasil (2012) Law no 12.651, de 25 may de 2012. http://www.planalto.gov.br/ccivil_03/_ato2011-2014/2012/lei/112651.htm

[18] The Angiosperm Phylogeny Group III (2009) An Update of the Angiosperm Phylogeny Group Classification for the Orders and Families of Flowering Plants: APG III. Botanical Journal of the Linnean Society, 161, 105-121. https://doi.org/10.1111/j.1095-8339.2009.00996.x

[19] Stage, A.R. (1973) Prognosis Model for Stand Development. USDA Forest Service Research Paper INT-173. Intermountain Forest \& Range Experiment Station, Forest Service, U.S. Department of Agriculture, Ogden, Utah.

[20] de Souza, A.L. and Soares, C.P.B. (2013) Native Forests-Structure, Dynamics and Management. Editora UFV, Viçosa.

[21] Pino, F.A. (2007) BINARY DECISION MODELS: A Review. Revista de Economia Agrícola, 54, 43-57.

[22] Gujarati, D.N. and Porter, D.C. (2011) Basic Econometrics. AMGH, Porto Alegre.

[23] Statacorp LP. (2011) Stata Statistical Software, Version 12.0. College Station, TX, E.U.A.

[24] Brancalion, P.H.S., Vidal, E., Lavorenti, N., Batista, J.L.F. and Rodrigues, R.R. (2012) Soil-Mediated Effects on Potential Euterpe edulis (Arecaceae) Fruit and Palm Heart Sustainable Management in the Brazilian Atlantic Forest. Forest Ecology and Management, Elsevier B. V., 284, 78-85. https://doi.org/10.1016/j.foreco.2012.07.028

[25] Brooker, R.W., Maestre, F.T., Callaway, R.M., Lortie, C.L., Cavieres, L.A., Kunstler, G., Liancourt, P., Tielbörger, K., Travis, J.M.J., Anthelme, F., Armas, C., Coll, L., Corcket, E., Delzon, S., Forey, E., Kikvidze, Z., Olofsson, J., Pugnaire, F., Quiroz, C.L., Saccone, P., Schiffers, K., Seifan, M., Touzard, B. and Michalet, R. (2007) Facilitation in Plant Communities: The Past, the Present, and the Future. Journal of Ecology, 96, 18-34.

[26] Harcombe, P.A., Bill, C.J., Fulton, M., Glitzenstein, J.S., Marks, P.L. and Elsik, I.S. (2002) Stand Dynamics over 18 Years in a Southern Mixed Hardwood Forest, Texas, 
USA. Journal of Ecology, 90, 947-957.

https://doi.org/10.1046/j.1365-2745.2002.00735.x

[27] Reis, A. (1995) Euterpe edulis Martius-(Palmae) Seed Dispersal in a Dense Montane Ombrophilous Forest of the Atlantic Slope in Blumenau, SC. Dissertation, Universidade Estadual de Campinas, Campinas. 